\title{
Structural strategies and measures reducing flood action on architectural heritage
}

\author{
M. Drdácký \& Z. Slížková \\ Institute of Theoretical and Applied Mechanics of the \\ Academy of Sciences of the Czech Republic, \\ ARCchip Centre of Excellence Telč, Czech Republic
}

\begin{abstract}
The paper systematically deals with structural measures which have been developed and/or designed for defined categories of architectural heritage objects sorted according to their sensitivity to flood action. There are distinguished i) flood resistant objects and structures, ii) objects and structures from materials with a high moisture volumetric change, iii) structures from materials of strength highly degrading due to moisture (including soils), iv) structures susceptible to partial damage due to flood, and v) structures and elements vulnerable to overall collapse or large displacement due to flood. Each category is illustrated with typical representatives and with typology of damage which may be caused by flooding. Then to each category and damage appropriate preventive or remedial measures are suggested, including recommendations related to overall risk management strategy. Special attention is paid to the state and condition of historic objects which are under threat of flooding, in many cases repeatedly. Several examples from recent damage on cultural heritage monuments due to natural disaster effects clearly show a very close dependence of the extent of damage on the previous restoration interventions and the health condition of the damaged monument. This statement is documented with data and facts observed during inspections on historic objects after flood, as well as data collected during a European FP6 CHEF joint research project in this field.
\end{abstract}

Keywords: cultural heritage protection, flood damage, preventive measures.

\section{Approach}

Preventive and temporary measures are typically sorted into two categories: structural and non-structural, i.e. rather organizational or operational 
(Drdácký et al. [1]). Structural measures are sometimes difficult to materialize in the case of cultural heritage protection because they are mostly visible and disturbing, and often not cost-effective. This subject needs further research and comparison to best practice non-structural measures. As far as non-structural measures are concerned, the application of standards to protect cultural heritage from flood leads to the problem that the originality, authenticity and aesthetic qualities and values of historic monuments should not be compromised. However, no European Standard is in practice available for effective protection of cultural heritage against flood. Nevertheless, standardization of some preventive processes and procedures, e.g. mapping and monitoring, would certainly bring positive results. Best practice is usually difficult to generalize in a sufficiently informative way. Some basic principles which have proved to be efficient can be learnt in various forms and from various media, (e.g. proceedings of specialized conferences, or the Internet). Let us summarize four pillars for mitigating generally any adverse natural disaster effects on cultural heritage according to the World Institute for Disaster Risk Management (USA):

i) regular inspection and careful maintenance of the historical stock and improved land use planning and management;

ii) raising awareness and regular coordinated training;

iii) international cooperation and availability of funding, and;

iv) legislative support.

Structural strategies and measures reducing flood action are suggested and designed selectively according to ranking of structures and elements vulnerable to flood effects as defined by the author elsewhere (Drdácký et al. [2]). Let us summarize them again:

F0 Flood resistant objects and structures; F1 Objects and structures from materials with a high moisture volumetric change, e.g. timber structures and elements, combined structures from different moisture expansion materials, some soils; F2 Structures from materials of strength highly degrading due to moisture, e.g. dried brick (adobe) masonry, masonry with clay (low lime or cement contents) mortars, decayed timber structures and elements, infill subsoil and fine particle subsoil; F3 Structures susceptible to partial damage due to flood, e.g. timber parts prone to uplifting and floating away, large bridges, pavements; F4 Structures and elements vulnerable to overall collapse or displacement due to flood, e.g. small bridges and walkways, free standing walls, light improperly anchored objects (summer-houses, etc.).

\section{Strategies and measures}

\subsection{Historical comments and introduction}

Guidelines or instructions how to behave during flood events are quite old and they mostly concern non-structural measures. In the Czech lands the first known case is from the 1538 and it is particularly focused on protection of ponds or lakes. Next governmental document is from the year 1542 and concerns river weirs which should be "opened during high water". Any of historical flood 
including very recent ones are to be carefully analysed in order to take lessons for improvements in flood management and preventive as well as post event measures. Such examples are reports by Thieken et al. [3] or by Messner and Meyer [4]. A guide for assessment on flood damage of cultural heritage properties has been suggested by Kelley [5], which is based on Mississippi 1993 flood experience and some flood consequences on Norwegian cultural heritage analysed by Mattsson and Oftedal [6]. There were several projects supported from the European Commission (EC) on flood risk management, for example a very detailed project FLOODsite which contains some tasks focused on mitigation flood damage but without specific relation to cultural heritage. For example, the damage evaluation systems and methods do not consider intangible cultural or environmental and natural heritage values. In fact, general nonstructural measures mostly improve the protection of cultural heritage, too. This paper takes advantage of the EC joint international project CHEF (Cultural heritage protection against flood) which was focused on cultural heritage, see Drdácký $[7,13]$.

\subsection{Regular inspection of structural health}

Regular inspection of structural health concerns all categories of cultural heritage objects endangered by possible flooding. Special attention is to be paid to the structural integrity of structures as dams, namely in relation to historical water works (ponds and channels), to bridges - namely when they are small and from light or water saturation sensitive materials. Defects and deficiencies identified during regular inspections must be repaired as soon as possible in order to keep historic objects well maintained and "healthy". In many cases the maintenance requires restoration interventions involving consolidation or strengthening of materials and structures. Such works should be done appropriately taking into account and assessing possible negative effects during emergency situations. The issue is discussed below in detail.

\subsection{Emergency plans and guidelines}

Emergency plans and guidelines - which must take into account not only all categories of cultural heritage objects but also movable heritage - are the most important preventive measures reducing the damage or loss substantially. In fact, in the last floods the majority of damage on cultural heritage has been experienced in relation to movable heritage, which could be totally saved if proper evacuation plans were elaborated (and the warning functioned reliably). In case of built environment, the guidelines are based on so called comprehensive flood risk management which recognizes that absolute flood prevention is unachievable and unsustainable because of the high costs and inherent uncertainties. Thus management aims at controlling the hazard on the one hand and lowering the vulnerability on the other hand (e.g. Hooijer et al. [8].

A very instructive guide has been issued by the UK Office of the Deputy Prime Minister "Preparing for floods" in 2003 [9] focused on improvement the 
flood resistance of domestic and small business properties. An example of guidelines specifically oriented to cultural heritage in relation to natural disasters it is the guide prepared by ICCROM or a more recent publication by the Federal Funding for Cultural Institutions "Before and After Disasters" [10]. Flood guidelines usually give advice how to save lives and property but not the cultural assets, especially when they are not in permanent use. It was approved recently during the flood in Bulgaria (Thieken et al. [3]). All emergency plans must be supported with maps of cultural heritage in the flooding zone with clearly categorized vulnerability and needs for emergency measures. Relevant transport means must be ensured for evacuation of movable heritage and adequate storage facilities prepared.

\subsection{Early warning and information systems}

As it already has been mentioned above the early warning and information systems represent indispensable and most important element of flood mitigation measures and affect all categories of cultural heritage objects. The majority of if not all - flood damage on movable heritage in Prague and Central Bohemia in the year 2002 was a consequence of totally failed warning and information services.

\subsection{Prepared technical means against flood}

Prepared technical means against flood are designed to prevent water inflow into the cultural heritage buildings or to the vicinity of such buildings. They are mostly a part of integral protection of a settlement and typically represented by stable walls and dams with moving gates or temporary walls with easy installation. In this category we also involve temporary barriers used for a tight closing of door or window openings by means of special shutters or using bags with sand. The technical means are applicable for all categories of objects.

\subsection{Temporary strengthening and additional supports}

Temporary strengthening and additional supports are required in case of protection of free standing sculptures or free standing walls. In the latter case it should be combined with execution of new inlet openings which help to balance the water pressure along both sides of a wall as well as empting the space behind the wall. The additional supports must not promote creation of dams from floating objects. Strengthening is used for to increase resistance of existing doors or light walls. Among the measures in this category we consider also surface protection of materials vulnerable to water with a possible washing out effects, e.g. adobe walls or bricks, infill layers and earth dams, as well as frescoes and similar surfaces. This measure is of importance also for stone walls with clay mortars, especially if used as retaining walls, where additional support is usually built. 


\subsection{Decreasing load}

Measures decreasing load of water pressure both static and dynamic are applied to protect mainly bridges, free standing walls and floors. It is recommended to dismantle parapet walls or rails as well as to remove sculptures on bridges in order to decrease the surface acting against the water flow, which helps not only to save the parapet walls and sculptures but also the bridge itself. In free standing walls the above mentioned temporary openings allow balancing of water pressure. This measure is useful also for protection of ground floor walls if they are highly or fully flooded. Here also the openings into the floor structure are recommended in order to decrease the uplift forces which may damage not only the floor but a whole object. Significant forces can be generated by volumetric changes of water soaking materials, namely by timber elements. This can be prevented by cutting sufficient dilatation gaps on the ends of timber beams or floors in order to allow their expansion without damaging surrounded masonry.

Among the measures in this category we should mention also a necessity to remove from the attics and floors all materials which are water susceptible and could increase the load of ceilings after the high water relief, e.g. high layers of hay, insulation mats capable to trap fine mud and similar. It is recommended to support temporarily also massive timber ceilings which may exhibit excessive deformations due to water saturation of wood and infill.

\subsection{Improved anchoring}

Improved anchoring of sensitive structural parts into supporting structures protects namely structures which may flow away, as e.g. light bridges and walkways, timber roofs, small timber structures and houses.

\subsection{Removal of floating objects from the stream}

Floating objects are very dangerous for bridges and should be removed from the stream. They may damage bridges as well as other objects in water by impact and they can accumulate before the bridge or other obstacle to create "dams" which increase the water pressure and can even elevate the water level. There are used cranes moving on the bridge and catching and transferring the floating object behind the bridge or away from the flooded area.

\subsection{Guidelines for "after the flood" activities}

The period after a flood event is very critical for cultural heritage objects of all categories. Therefore, guidelines for "after the flood" activities are necessary. They advice problems, e.g. preventing damage from fast settlement, in-time repair of potentially dangerous damage and failures, optimization of drying procedures to avoid material disintegration or biodegradation, fast salt crystal growth and desalination, corrosion due to water pollution and climatic effects, etc. 


\section{Structural preventive and temporary measures for immovable heritage}

\subsection{Flood resistant objects and structures (F0)}

Even flood resistant objects and structures require specific preventive or temporary measures. If located on sites with a high probability of inundation they presumably had to survive several historic floods and the best way of their protection seems to be keeping them as much as possible in the state which proved to be flood resistant. This is valid especially in the cases of a very high water when it is not possible to avoid flooding of the interior. However, such objects may be immersed into shallow water during flood situations, too, and their external as well as interior structures, materials and artistic decorations are in a danger of watering. The measures start with attempts of tightening all inlets with temporary or prepared and built-in shutters of doors and windows. The measure is combined with strengthening of glazing and building of sand sac barriers. Floor plates are to be temporary reinforced and supported against water pressure uplift forces. Further, it is absolutely necessary to reduce to a minimum the flooding water pollution. Therefore, all sew pipe system openings must be closed and tighten, which might be supported with automatic one way sew pipe valves. Even these objects may carry important cultural heritage details or information which could be seriously damaged or lost due to flood action. Artistic details, wooden floors, surface paints or frescoes as well as just a naked surface of natural stones may suffer from physical, chemical or biological attack during and after flooding. If acceptable, the surface of sensitive artistic objects can be pre-treated by hydrophobic agents or prevented from direct action of the high water by means of wrapping into tight plastic foils. In the case of full flooding, it is recommended to open, unhinge and fix in storing the doors otherwise high water does it and the floating door wings may block the other door after the water decline. The objects must be guarded and protected against robbery during flood situations because the flooded objects are frequently easily accessible by boats and through windows on levels of higher floors, usually inaccessible. Evacuation of furniture and other moveable objects, e.g. books from cellar and ground floor spaces must be planned and controlled in a way which prevents possible overloading of floor structures in higher stories and ground floor masonry due to inappropriate increase of live load in upper parts of a building.

\subsection{Objects and structures from materials with a high moisture volumetric change (F1)}

\subsubsection{Timber structures and elements}

Massive timber elements, as e.g. joists or logs, when wetted expand differentially in all directions. If such elements are freely supported this geometrical change is more or less reversible and the massive elements after drying reach almost the same form as before wetting. On the other hand, the plated wooden elements not 
only expand but usually distort and they never return by simple drying into the original shape. Therefore, such structures are to be evacuated, if possible. The floors represent a special case being usually composed of wooden elements assembled frequently in several layers of non-coincident wood fibre orientation, which helps to prevent severe distortion. The floors tend to bow and this can be prevented by means of creating sufficient dilation gaps along the perimeter of the floor between the floor structure and the walls.

\subsubsection{Combined structures from different moisture expansion materials}

The above mentioned floor between masonry walls is an example of a combined structure from the flood behaviour point of view. In fact, any combination of timber elements with masonry is a combined structure from different moisture expansion materials. Wetting causes expansion and if this is constrained an excessive deformation or even a failure occurs. Thus the only possible preventive measure consists of creating dilation gaps and free supports. The forces created by expanding wood may reach quite high values which may easily destroy masonry, therefore, this type of risk must be carefully evaluated and adequately treated.

\subsubsection{Some soils}

Expandable soils, e.g. clays, may cause defects on building foundations and/or damage geotechnical structures. They usually react slowly and the adverse effects occur with a delay, so in this case a fast drainage during and after the flood helps to control the soil behaviour. Relevant preventive measures are suggested in a special chapter.

\subsection{Structures from materials of strength highly degrading due to moisture (F2)}

\subsubsection{Dried brick (adobe) masonry}

Water saturation of dried brick has detrimental effect on their mechanical characteristics and the structures from adobe may fail very quickly. Especially in situations when the wetting is accompanying with mechanical action of a water stream. Experience from recent floods shows that adobe masonry plastered with water resistant, e.g. lime mortar, plaster sustains flooding without serious defects. Therefore, it might be recommended to strengthen adobe masonry by temporary confining jacketing together with a surface protection against direct contact of the dried brick with water. Further, recent studies on adobe consolidation (Ferron [11]) proved positive effects of surface treatment by gelatine and ethyl silicates on wet-dry cycling. It indicates that in dangerous areas the adobe could be chemically protected, too.

\subsubsection{Masonry with clay (low lime or cement contents) mortars}

Brick or stone masonry built using clay mortars is very sensitive to flood action, too. Especially irregular stone multiple leaf masonry may easily loos its load carrying capacity in flood situations. Preventive measures include the same tips as in the case of adobe masonry. 


\subsubsection{Brick or stone masonry}

Even the regular burnt brick or some water sensitive stone masonries decrease their strength due to water saturation. This loss of load carrying capacity may reach up to about $50 \%$ of the capacity in dry condition. Therefore, all masonry buildings in possibly inundated areas should be inspected and examined from the point of view of possible degradation when flooded. Namely the load carrying capacity of wet pillars should be assessed, and in cases of their insufficient strength they must be temporarily strengthened or additional supports must be installed. Such required measures must be included in the inundation maps and emergency plans.

\subsubsection{Decayed timber structures and elements}

Decayed timber (regardless the biodegrading agent - fungi or insects) has typically a lower density and a higher water absorption. Moreover, its strength is decreased, too. Such timber is soaking quite high amounts of water, its dead load is increasing and the structure or structural element tends to break and collapse. It is recommended to support temporary ceiling joists and girders. This measure also reduces excessive deflections.

\subsubsection{Infill subsoil and fine particle subsoil}

The subsoil and foundation instabilities represent one of the major threats to architectural heritage during flood situations. Here controlled and rather slow pumping of water from cellars reduces the danger of washing out fine particles and prevents remarkable damaging compacting and subsidence, (Drdácký [12]). Shallow foundation of partition walls on infill, which frequently occurs in historical architecture, can be strengthened only by underpinning or by improvement of infill by means of grouting.

\subsection{Structures susceptible to partial damage due to flood (F3)}

\subsubsection{Timber parts prone to uplifting and floating away}

Timber roofs, sculptures, free standing stairs, platforms and similar objects are under threat of their uplifting and floating away. Their anchoring should be inspected, well maintained and in-time repaired or even strengthened against flood effects.

\subsubsection{Buildings of insufficient robustness}

It has been observed that in particular lack of structural robustness might have led to failures of historic or just old buildings. For example, in masonry structures such a lack of robustness is represented by missing collar beams. Structural robustness may be improved by adequate: i) system of horizontal and vertical ties, ii) increased resistance of key members (a member essentially important for the structural robustness in the way that failure of this member implies a failure of a whole structure or significant parts of it), iii) secondary protection of key members, and iv) invulnerable structural detailing. 


\subsubsection{Large bridges}

Large bridges usually sustain floods quite well. However, they are under threat of partial damage, namely their foundations and parapet walls (see free standing walls). Only foundations of bridge piers are extremely vulnerable and the foundation undermining is a very frequent case which may cause partial collapse of some parts of a bridge. Undermining is prevented by improving soil characteristics under the foundations, and traditionally by means of deep barriers around piers and by creation of small islets with paved upper surface. Light chain or suspension bridges should be protected be decreasing potential water stream loads and, therefore the rails should be temporarily removed.

\subsubsection{Pavements}

Local failure of street and river bank pavement involves mainly surface erosion by the water stream, infill or fine soil compacting, suffusion or internal erosion usually in areas of not properly compacted infill after construction activities or distribution line digging. Here again the subsoil characteristics might be improved by means of grouting (silicate or polymer based). Grouting may be combined with the application of grouting tubes drilled into a ground and left there as strengthening "scaffolding" after the use for grouting. Polyurethane resins are frequently used for such a preventive or remedial work. It is very important to keep the pavement surface and area in perfect conditions, which is based on regular inspection and early repair or regular maintenance.

\subsection{Structures and elements vulnerable to overall collapse or displacement due to flood (F4)}

\subsubsection{Small bridges and walkways}

Small bridges and walkways can be preventively protected in the same way as large bridges, i.e. by measures decreasing their load (dismantling the rails and/or parapet panels). If possible, some measures declining the direct water stream actions might be temporary built, as well as systems catching floating object. However, this category of objects is usually severely damaged or lost, therefore any precious elements or objects of art should be removed and placed into temporary stores.

\subsubsection{Free standing walls}

In the case of free standing walls balancing water pressure is necessary. This is usually achieved by openings allowing flowing water behind a wall. Short walls, namely the walls in lower floors of buildings might be effectively temporarily strengthened. Walls built with an axis perpendicular to the main water stream direction are to sustain pressure loads which are higher than the pressure from simple immersion not only due to the dynamic action of the mass of water (Fig. 1). The water depth is increased by the backwater effect which might substantially contribute to the water pressure and must be taken into account when designing temporary cellar or ground floor walls strengthening. Parapet walls on bridges may be dismantled and after the flood built up again. In any 


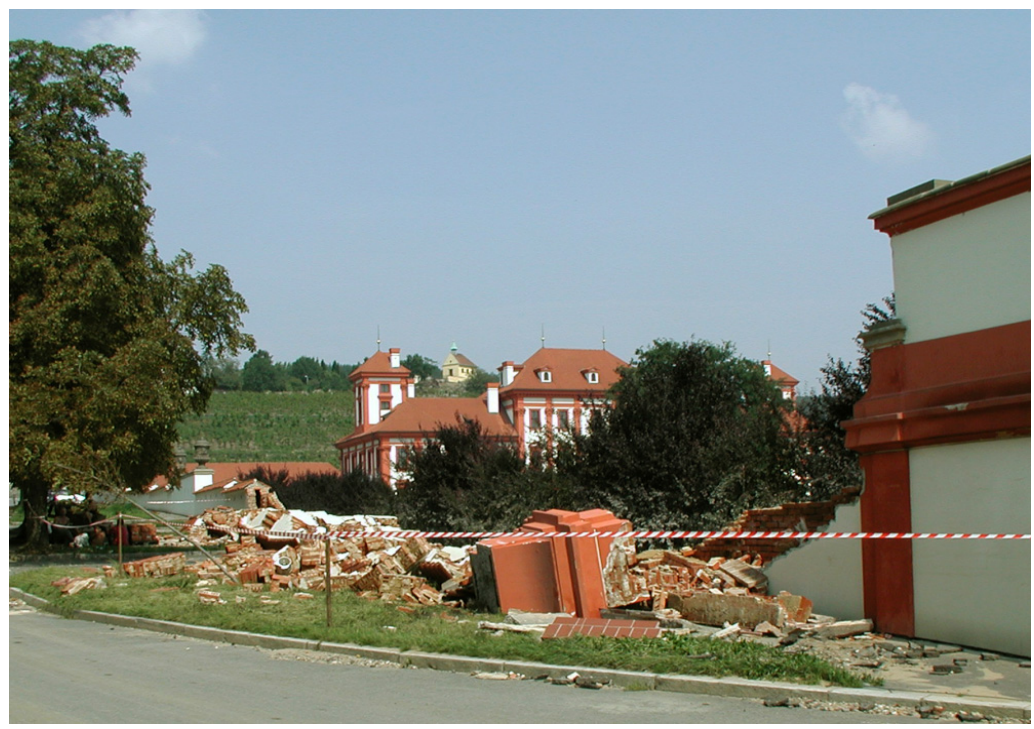

Figure 1: $\quad$ Failed garden wall subjected to water pressure and flow.

case a perfect documentation and even marking of individual stones is useful for an easier assembly after a possible failure.

\subsubsection{Light improperly anchored objects}

Light objects as, e.g. summer or garden-houses, etc. should be properly anchored to the foundations. They will be very likely transported away and it is recommended to evacuate all moveable objects or art and architectural details which might be lost.

\section{Combined inappropriate conservation with neglected maintenance}

Several examples from recent damage on cultural heritage monuments due to natural disaster effects clearly show a very close dependence of the extent of damage on the previous restoration interventions and the health condition of the damaged monument (Drdácký et al. [1]). The second author analysed damage on historic objects in the Château Veltrusy park near Prague which were severely damaged by the flood in 2002. There was remarkable difference between objects which had been properly restored before the flood, e.g. a stone bridge with Sphinx, and objects which were neglected or incorrectly restored, e.g. sculptures on the Château monumental stairs, Fig. 2. Even though the bridge was totally immersed in a high water stream, it needed to be only cleaned with water and low pressure steam. In 2004 some hair cracks and slight mortar disintegration were visible in masonry joints. After repeated flooding in 2006 the bridge was only slightly restored (colour retouch, plaster repair). On the other hand, the 
sculptures were repaired long before the 2002 flood in a way which applied Portland cement and polyvinylacetate consolidation which substantially decreased water and vapour permeability and kept water inside the material. This increased contamination by salts, bio-colonization and surface detachment and disintegration patterns up to $3 \mathrm{~m}$ height. Freezing, moisture dilation and crystallization damage required a very substantial restoration intervention after the flood situation.

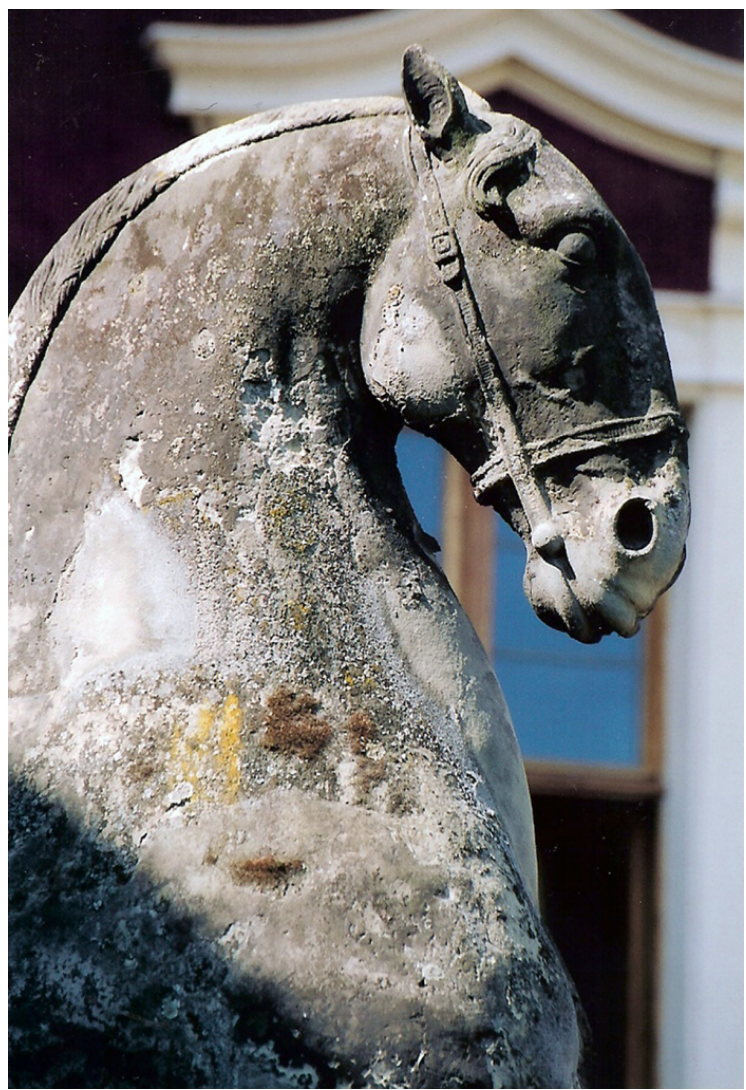

Figure 2: Increased contamination by salts, bio-colonization and surface detachment and disintegration patterns due to inappropriate restoration and treatment before flooding.

\section{Acknowledgements}

The authors gratefully acknowledge support from Institutional research plan grant RVO 68378297 including the CET EC Structural Fund project CZ.1.05/1.1.00/02.0060 and the CHEF Project of the 6th Framework Programme on Research and Technology Development of the European Commission (Contract No. 044251). 


\section{References}

[1] Drdácký, M., Binda, L., Herle, I., Lanza, L.G., Maxwell, I., Pospíšil, S., Protecting the Cultural Heritage From Natural Disasters, Study of the European Parliament IP/B/CULT/IC/2006_163, p. 100, February 2007.

[2] Drdácký, M., Herle, I., Pospíšil, S., Sližková, Z., Protecting cultural heritage against natural hazards. Keynote Papers "Seismic protection of cultural heritage", Proc. of the 2nd WCCE-ECCE-TCCE Joint Conference, Turkish Chamber of Civil Engineers: Ankara, pp. 103-122, 2011.

[3] Thieken, A.H., Brito, J.-M., Blanchais, J.-M., Morris, K., Vlahov, M., ten Brinke W.B.M., Flood Mission Bulgaria 25th to 29th July 2005, Final Report, EU Member States Experts - GFZ Potsdam (Germany), Centre national des Ponts de Secours (France), BCEOM (France/Bulgaria), Environment Agency (UK), Ministry of Transport, Public Works and Water Management (The Netherlands), 2005.

[4] Messner, F., Meyer, V., Flood damage, vulnerability and risk perception challenges for flood damage research, UFZ: Discussion papers, 2005.

[5] Kelley, S.J., Curriculum on flood damage assessment of cultural heritage properties, National Trust for Historic Preservation: 14 p., 1994.

[6] Mattsson, J., Oftedal, T., Research on biodeterioration of cultural heritage in Norway. Proc., European research on cultural heritage - State-of-theArt Studies, ed. M. Drdácký, Vol.2, ITAM: Prague, pp. 477-480, 2004.

[7] Drdácký, M., Impact of Floods on Heritage Structures. J. Perf. Constr. Fac. 24 (5), pp. 430-431, 2010.

[8] Hooijer, A., Klijn, F., Kwadijk, J., Pedroli, B. (eds.), Towards sustainable flood risk management in the Rhine and Meuse River basins. Report IRMA-SPONGE research programme, NCR-publication 18-2002, $39 \mathrm{p}$., 2002.

[9] Preparing for floods, Office of the Deputy Prime Minister, 2003, www.odpm.gov.uk

[10] Federal Emergency Management Agency, Before and After Disasters. FEMA 533: September 2005, www.heritageemergency.org

[11] Ferron, A., The Consolidation of Earthen Surface Finishes: A Study of Disaggregating Plasters at Mesa Verde National Park, MSc Thesis, University of Pennsylvania, p.144, 2007.

[12] Drdácký, M., Flood Damage to Historic Buildings and Structures. J. Perf. Constr. Fac. 24 (5), pp. 439-445, 2010.

[13] Drdácký, M., Binda, L., Hennen, I.Ch., Köpp, Ch., Lanza, L.G., Helmerich, R. (eds.), CHEF - Cultural Heritage Protection Against Flooding, ITAM: Prague, 229 p., 2011. 